\title{
Transperineal rectocele repair is ideal for patients presenting with fecal incontinence
}

\author{
Marie Shella De Robles ${ }^{1}$, Christopher J. Young ${ }^{1,2}$ \\ ${ }^{1}$ Department of Colorectal Surgery, Royal Prince Alfred Hospital, Sydney, NSW; ${ }^{2}$ The University of Sydney, Discipline of Surgery, Sydney, \\ NSW, Australia
}

Purpose: Rectocele can be associated with both obstructed defecation and fecal incontinence. There exists a great variety of operative techniques to treat patients with rectocele. The purpose of this study was to evaluate the clinical outcome in a consecutive series of patients who underwent transperineal repair of rectocele when presenting with fecal incontinence as the predominant symptom.

Methods: Twenty-three consecutive patients from April 2000 to July 2015 with symptomatic rectocele underwent transperineal repair by a single surgeon.

Results: All patients had a history of vaginal delivery, with or without evidence of associated anal sphincter injury at the time. The median age of the cohort was 53 years (range, 21-90 years). None were fully continent preoperatively. However, continence improved to just rare mucus soiling or loss of flatus in all patients 6 months after their surgery. There was no operative mortality. Postoperative complications including urinary retention and wound dehiscence occurred in 3 patients.

Conclusion: Fecal incontinence associated with rectocele is multifactorial and may be caused by preexisting anal sphincteric damage and attenuation. Our experience suggests that transperineal repair provides excellent anatomic and physiologic results with minimal morbidity in selected patients presenting with combined rectocele and anal sphincter defect.

\section{Keywords: Rectocele; Anal sphincter injury; Transperineal rectocele repair; Overlapping sphincter repair}

\section{INTRODUCTION}

Pelvic floor disruption among females is generally attributed to childbirth. If there is anal sphincter damage recognized at the time of delivery, it is usually addressed by the attendant obstetrician. However, patients often present with symptoms of fecal incontinence and difficulty in evacuation much later. A rectocele represents a pulsion diverticulum of the lower anterior rectum caused by a defect in the midline anterior rectal muscle wall [1]. The rectal mucosa herniates through this defect and may extend

Received: Mar 2, 2021 - Revised: Apr 22, 2021 - Accepted: May 1, 2021 Correspondence to: Marie Shella De Robles, M.D., DPBS, FRACS Department of Colorectal Surgery, Royal Prince Alfred Hospital Medical Centre, Suite G07/100 Carillon Avenue, Newtown, NSW 2042, Australia Tel: +61-2-95190064, Fax: +61-1300-078746

E-mail: shella.derobles@gmail.com

ORCID: https://orcid.org/0000-0001-5753-8344

(C) 2022 The Korean Society of Coloproctology

This is an open-access article distributed under the terms of the Creative Commons Attribution NonCommercial License (https://creativecommons.org/licenses/by-nc/4.0) which permits unrestricted noncommercial use, distribution, and reproduction in any medium, provided the original work is properly cited. into the internal and external anal sphincters. In general, obstructive defecation is related to the rectocele while fecal incontinence is attributed to the anal sphincter defect.

These disorders socially and psychologically torment patients and significantly impair their quality of life. Medical and behavioral therapy with a high fiber diet, laxatives, enemas, and biofeedback are the initial management strategy for these patients. Surgery is considered when conservative therapy fails particularly for those with severe symptoms and have repairable anatomic defects. There are several surgical approaches to manage this including the traditional transanal vertical and horizontal plication of the rectovaginal septum, rectal resection using endostaplers, transvaginal posterior colporrhaphy, and transperineal anterior levatorplasty.

The surgical management of rectocele and anal sphincter defect is a significant challenge for the patient and the surgeon. It is important to balance the anticipated improvement in the quality of life with a minimal acceptably low surgical morbidity. No single surgical technique has so far emerged as the optimal approach to repair rectocele in patients with postpartum fecal incontinence. 
Volume 38, Number 5, 2022

The transverse transperineal approach is a strategy that allows wide mobilization of rectal and vaginal tissues, and simultaneous repair of the rectocele and anal sphincter defect. This paper will outline the key surgical steps for transperineal rectovaginal reinforcement and repair of the external sphincter using the overlapping technique. We have used this technique in patients with rectocele and anal sphincter defect for the past several years and recently reviewed our results.

\section{METHODS}

This is a retrospective cohort study of consecutive patients from April 2000 to July 2015 who underwent transperineal repair of both rectocele and anal sphincter defect by a single surgeon. Data collected for patient characteristics include age, indication for surgery, and postoperative complications. Patients' data were obtained from their hospital records and the consulting surgeon's office.

Preoperative anorectal manometry and endoanal ultrasonography were performed in all patients. Electromyography and nerve conduction studies were also used to evaluate atrophy of the pelvic floor muscles or pudendal terminal motor latency to determine causes of pelvic floor weakness. Preoperative defecography was performed at rest and on maximal squeeze and strain. For patients with obstructed defecation associated with anal incontinence, the transperineal approach was performed to repair the rectocele with either an anterior external overlapping sphincteroplasty or levatorplasty.

\section{Operative technique}

Prophylactic antibiotic was given to all patients on induction of

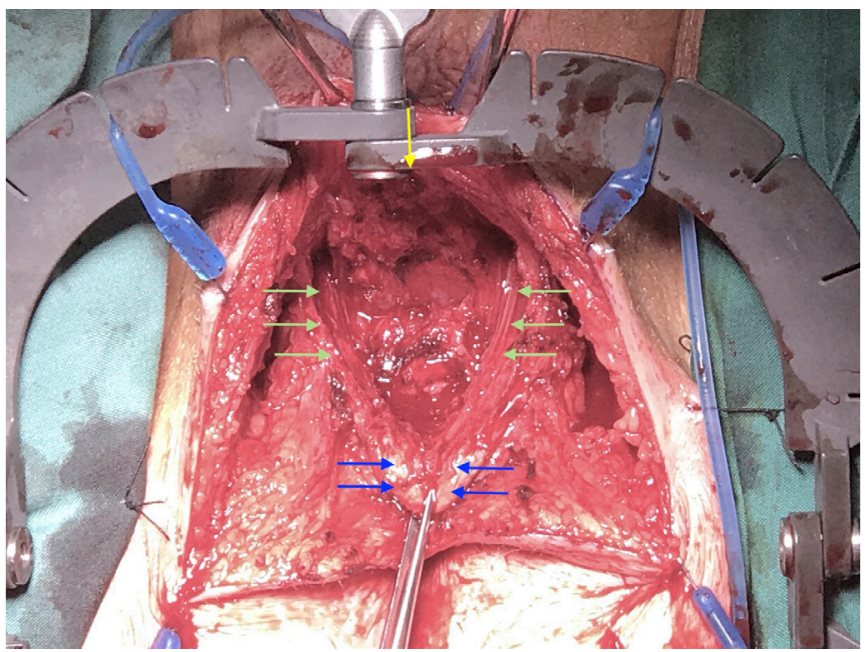

Fig. 1. The transperineal dissection is extended to the vaginal apex (yellow arrow) to expose the rectocele, the perirectal fascia, the levator arc (green arrows), and the anal sphincters (blue arrows). The upper limit of the rectocele is identified as divergence of the longitudinal muscle of the lower rectum. general anesthesia. With the patient placed in lithotomy position, a transverse perineal incision is made. The plane between the external anal sphincter and the posterior vaginal wall is developed with diathermy ensuring adequate hemostasis. The dissection is extended to the vaginal apex to expose the rectocele, the perirectal fascia, and the levator arc (Fig. 1). The upper limit of the rectocele is identified as divergence of the longitudinal muscle of the lower rectum. The repair starts at this point and is plicated from proximal to distal in the midline until the rectocele is obliterated, the longitudinal muscle of the rectum approximated, and distally the internal anal sphincter reconstructed. This external anal sphincter is approximated using an overlapping repair in which the disrupted ends of the sphincter were mobilized and wrapped around each other (Fig. 2). Skin closure is done using interrupted absorbable sutures (Fig. 3).

All patients were seen routinely in the consulting room and reviewed initially after 6 weeks then after 6 months. Patients were subsequently followed up on an ad hoc basis or during consultations for other complaints.

This study was approved by the Sydney South West Area Health Service Ethics Review Committee (RPAH Zone; No. X18-0355). Waiver of consent granted by the Committee as the research presents no more than minimal risk of harm to subjects and involves no procedures for which written consent is normally required outside the research context.

\section{RESULTS}

A total of 23 female patients aged 21 to 90 years underwent transperineal repair of rectocele and anal sphincter defect from April

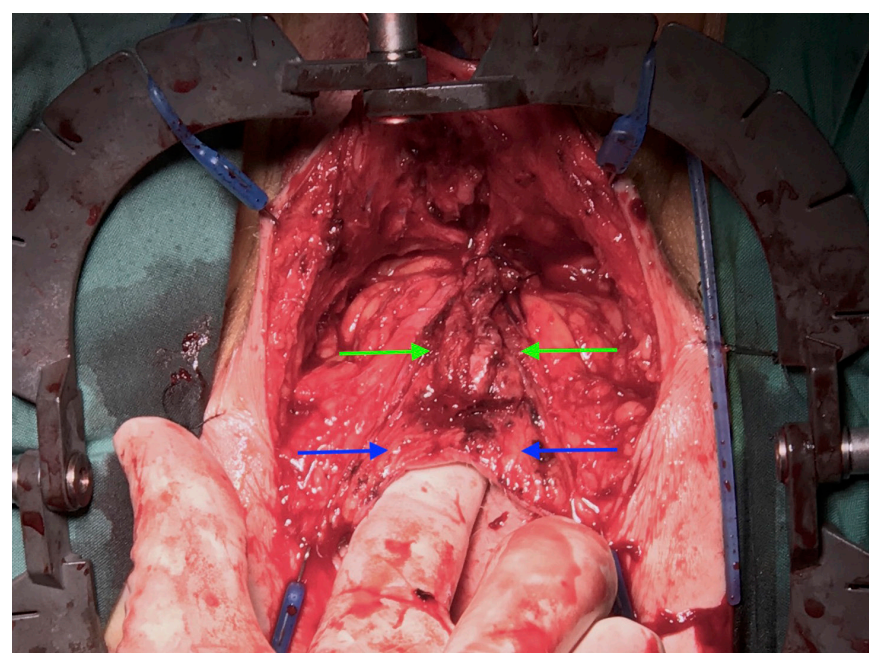

Fig. 2. After approximation of the longitudinal muscles of the rectum (green arrows), the external anal sphincter is approximated using an overlapping repair in which the disrupted ends of the sphincter were mobilized and wrapped around each other (blue arrows). 


\section{Coloptoctionator \\ Transperineal rectocele repair is ideal for patients presenting with fecal incontinence}

\section{Coloproctology Marie Shella De Robles, et al}

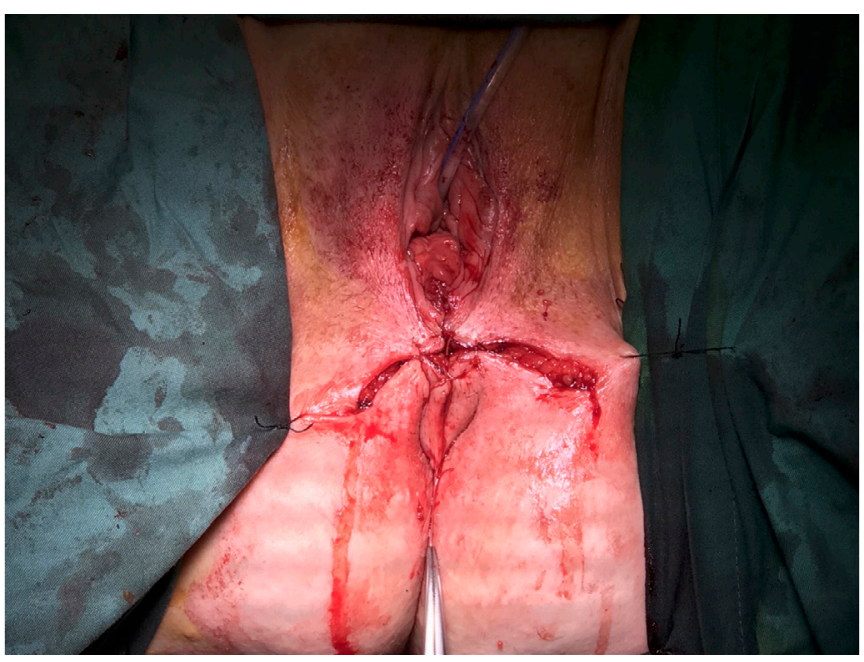

Fig. 3. Skin closure is done using interrupted absorbable sutures.

2000 to July 2015 by a single surgeon (Table 1). All patients had a history of vaginal delivery, with or without evidence of associated anal sphincter injury at the time. The median operating time and length of hospital stay were 2 hours and 7 days respectively. Two patients developed urinary retention postoperatively which required temporary bladder catheterization. One patient had wound separation which was managed by absorbent dressing applied by the patient and her carer. There was no operative mortality.

In all patients with rectocele, there was a concomitant anal sphincter disruption. None of the patients were fully continent preoperatively. In all cases, it was deemed socially unacceptable and had restricted the patient's lifestyle preoperatively. The patients with difficulty in evacuation used various forms of vaginal digitation or perineal support. After surgery, incontinence scores improved to just rare mucus soiling or loss of flatus. The mean \pm standard deviation of recorded Wexner score (preoperative, $17.09 \pm 1.31$ and postoperative, $5.83 \pm 1.90$ ) showed that transperineal levatorplasty resulted in an improvement in fecal incontinence $t(23)=-20.00, \mathrm{P}<0.00001,6$ months after surgery.

\section{DISCUSSION}

Rectocele is common in parous women and is assumed to be due to distension or tearing of the rectovaginal septum in labor and vaginal birth. A minor rectocele has been reported in as many as $93 \%$ of females [2]. However, the overall prevalence of rectocele is not well defined as many women are asymptomatic and do not seek medical consult. Known risk factors include primiparity, high fetal birth weight, prolonged second stage of delivery, instrumental vaginal delivery, and midline episiotomy [3, 4]. Defects of the rectovaginal septum have also been found to occur in asymptomatic, young nulliparous women [5]. However, parturition and childbirth seem to compound the size of such defects by the constant increased downward displacement of the pelvic floor and
Table 1. Baseline characteristics of patient undergoing transperineal levatorplasty

\begin{tabular}{lc}
\hline Characteristic & Data $(\mathrm{n}=23)$ \\
\hline Duration of symptoms $(\mathrm{mo})$ & $43.6 \pm 14.2$ \\
Preoperative Wexner score & $17.1 \pm 1.3$ \\
Rectocele size in defecography $(\mathrm{cm})$ & $4.7 \pm 0.9$ \\
Anal manometry & \\
Rest pressure $(\mathrm{mmHg})$ & $56.3 \pm 7.7$ \\
Squeeze pressure $(\mathrm{mmHg})$ & $112.4 \pm 13.8$ \\
Desire to defaecate volume $(\mathrm{mL})$ & $80.3 \pm 12.6$ \\
Maximum tolerable volume $(\mathrm{mL})$ & $154.5 \pm 35.9$ \\
\hline
\end{tabular}

Values are presented as mean \pm standard deviation.

rectum. Other possible etiologies of rectocele are chronic increase in abdominal pressure, prolonged orthostatic posture, or congenital or inherited weakness in the pelvic support system.

Surgical intervention is reserved for patients who have anatomical defects, pathologic conditions that can be corrected surgically, and those in whom conservative management has failed. The rectocele and anal sphincter defect when present should be repaired at the same time. The transperineal repair appears to be ideal for such cases. In this approach, addressing the rectocele first makes the anal sphincter anatomy easier to demonstrate, and extensive lateral dissection is avoided. Postoperative complications may include constipation, incontinence, incomplete rectal emptying, splinting, pain, bleeding, and sexual dysfunction. Early recurrence of a rectocele is most likely the result of missed and unrepaired support defects. Rectoceles that occur late after repair are usually due to constitutional factors, such as weakening of the supporting tissue because of advancing age, chronic straining, postmenopausal atrophy, and other factors.

Overlapping sphincteroplasty restores the anatomical integrity of the anal sphincter complex and is ideal for patients with sphincter defect secondary to traumatic childbirth or prior anal surgery. Associated risks of the procedure include bleeding, infection, pain, dyspareunia, and occasionally may cause fistula to the vagina [6]. One randomized trial comparing operative techniques for patients who had end-to-end and overlapping sphincter repair reported flatus incontinence in 39\% and 61\% respectively at 6 months, and $39 \%$ and $43 \%$ at 3 years [7]. The extent of sphincter damage, operative vaginal delivery, older age, and high body mass index are associated with the risk of fecal incontinence after primary repair. Despite worsening results over time, most patients remain satisfied with their surgical outcome after repair. A systematic review of 16 studies comprising of nearly 900 repairs reported a poor correlation between the patients' quality of life and the severity of fecal incontinence after anal sphincter repair. Overall, there was high patient satisfaction even if the fecal incontinence declined with time or adaptive measures were needed [8]. In older women, there is a tendency to recurrence of pelvic floor 
weakness, and surgery has been associated with worse functional outcomes [9]. Reinforcement with an absorbable mesh seems an attractive option to help strengthen the middle pelvic compartment and prevent subsequent prolapse. A prospective study of 25 patients who underwent transperineal repair of rectocele, 5 of which with prosthetic mesh, demonstrated that patients reported improvement in terms of feeling of incomplete emptying, prolonged and unsuccessful straining at stool and digital assistance after a median follow-up of 45 months, with acceptable morbidity [10]. However, this aspect requires further careful study.

There are little data concerning patients with rectocele who have associated fecal incontinence. Our experience suggests the transperineal repair provides excellent anatomic and physiologic results with minimal morbidity. However, because none of the patients gained full continence postoperatively, pelvic floor rehabilitation might be also needed to achieve better sphincter function in patients with fecal incontinence.

\section{CONFLICT OF INTEREST}

No potential conflict of interest relevant to this article was reported.

\section{FUNDING}

None.

\section{REFERENCES}

1. Mills RP. Rectocele and anal sphincter defect: surgical anatomy and combined repair. S Afr J Surg 2011;49:182-5.

2. Palit S, Bhan C, Lunniss PJ, Boyle DJ, Gladman MA, Knowles $\mathrm{CH}$, et al. Evacuation proctography: a reappraisal of normal variability. Colorectal Dis 2014;16:538-46.

3. de Leeuw JW, Struijk PC, Vierhout ME, Wallenburg HC. Risk factors for third degree perineal ruptures during delivery. BJOG 2001;108:383-7.

4. Stedenfeldt M, Pirhonen J, Blix E, Wilsgaard T, Vonen B, Øian P. Episiotomy characteristics and risks for obstetric anal sphincter injuries: a case-control study. BJOG 2012;119:724-30.

5. Dietz HP, Clarke B. Prevalence of rectocele in young nulliparous women. Aust N Z J Obstet Gynaecol 2005;45:391-4.

6. Burgio KL, Borello-France D, Richter HE, Fitzgerald MP, Whitehead W, Handa VL, et al. Risk factors for fecal and urinary incontinence after childbirth: the childbirth and pelvic symptoms study. Am J Gastroenterol 2007;102:1998-2004.

7. Farrell SA, Flowerdew G, Gilmour D, Turnbull GK, Schmidt MH, Baskett TF, et al. Overlapping compared with end-to-end repair of complete third-degree or fourth-degree obstetric tears: threeyear follow-up of a randomized controlled trial. Obstet Gynecol 2012;120:803-8.

8. Glasgow SC, Lowry AC. Long-term outcomes of anal sphincter repair for fecal incontinence: a systematic review. Dis Colon Rectum 2012;55:482-90.

9. El-Gazzaz G, Zutshi M, Hannaway C, Gurland B, Hull T. Overlapping sphincter repair: does age matter? Dis Colon Rectum 2012;55:256-61.

10. Lechaux JP, Lechaux D, Bataille P, Bars I. Transperineal repair of rectocele with prosthetic mesh. A prospective study. Ann Chir 2004;129:211-7. 